\title{
Management and perception of therapeutic adherence of breakthrough cancer pain by oncologists in Spain
} Manejo y percepción de la adherencia al tratamiento
del dolor irruptivo oncológico por oncólogos españoles

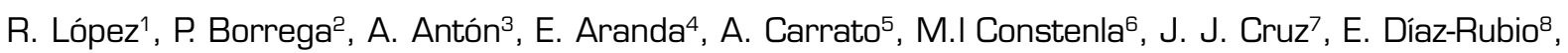
M. Feyjóo $0^{9}$, J. García-Foncillas ${ }^{10}$, P. Gascón ${ }^{11}$, V. Guillem ${ }^{12}$ y C. Camps ${ }^{13}$

${ }^{1}$ Fundación ECO. Servicio de Oncología Médica. Hospital Clínico Universitario de Santiago de Compostela.

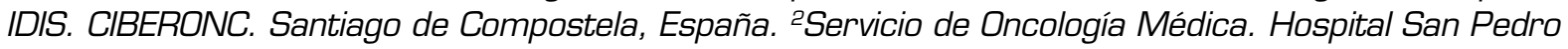

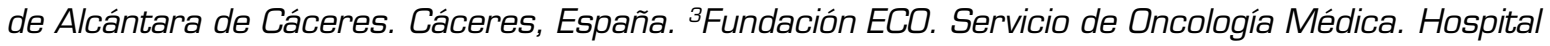
Universitario Miguel Servet. Zaragoza, España. ${ }^{4}$ Fundación ECO. Servicio de Oncología Médica. Hospital Reina Sofía. Córdoba, España. ${ }^{5}$ Fundación ECO. Servicio de Oncología Médica. Hospital Ramón y Cajal. Madrid, España. ${ }^{6}$ Fundación ECO. Servicio de Oncología Médica. Hospital Provincial de Pontevedra. Pontevedra, España. 'Fundación ECO. Servicio de Oncología Médica. Complejo Asistencial Universitario de Salamanca. Salamanca, España. ${ }^{8}$ Fundación ECO. Instituto de Investigación Sanitaria del Hospital Clínico San Carlos. Centro de Investigación Biomédica en Red en Oncología. Instituto de Salud Carlos III. Madrid, España. ${ }^{9}$ Fundación ECO. Servicio de Oncología Médica. Hospital Universitario La Moraleja. Madrid, España.

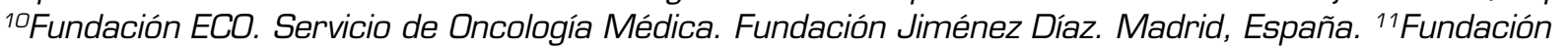
ECO. Oncología Molecular y traslacional. Institut d'investigacions Biomèdiques August Pi i Sunyer. Barcelona,

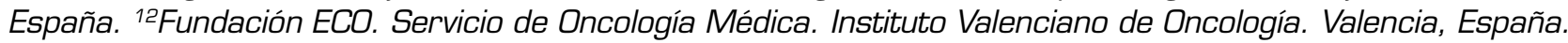
${ }^{13}$ Fundación ECO. Servicio de Oncología Médica. Hospital General de Valencia. Valencia, España

\section{ABSTRACT}

Objectives: The objective of this study was to evaluate the perception of oncologists on adherence to opioid treatment for breakthrough cancer pain (BTcP) in current clinical practice. Our study also included an assessment of other aspects of the management of BTcP, such as the reasons for non-adherence, the adequacy of the treatment, or the possible interventions required to improve adherence.

Methods: This observational, multicentric study was carried out in 84 hospitals throughout Spain. Oncologists were surveyed by means of an online questionnaire on their management of background cancer pain and BTcP, and their perception of adherence to the treatments.

\section{RESUMEN}

Introducción: El objetivo de este estudio fue evaluar la percepción de los oncólogos sobre la adherencia al tratamiento con opioides para el dolor irruptivo oncológico (DIO) en la práctica clínica real. El estudio también incluyó una evaluación de otros aspectos del manejo del DIO, como las razones de la no adherencia, la adecuación del tratamiento, o las posibles intervenciones necesarias para mejorar la adherencia.

Métodos: Este estudio observacional multicéntrico se realizó en 84 hospitales de toda España. Los oncólogos fueron encuestados por medio de un cuestionario online sobre su manejo del dolor oncológico basal y del DIO, y su percepción de la adherencia a los tratamientos.
López R, Borrega P, Antón A, Aranda E, Carrato A, Constenia MI, Cruz JJ, Díaz-Rubio E, Feyjóo M, García-Foncillas J, Gascón P, Guillem V, Camps C. Management and perception of therapeutic adherence of breakthrough cancer pain by oncologists in Spain. Rev Soc Esp Dolor. 2021;28(1):19-26
Recibido: 09-06-2020

Aceptado: 03-12-2020

Correspondencia: Rafael López rafa.lopez.lopez@gmail.com 
Results: Oncologists ( $\mathrm{N}=97$ ) reported that their first choice for BTcP was fentanyl (various formulations], with high perceived tolerance ( $>76 \%$ of patients). Most oncologists (96.8\%) evaluated adherence in their patients but only 69. 1\% always prescribed medication to prevent adverse effects of opioids and only $74.2 \%$ always titrated the minimum dose. Most oncologists (51.0\%) perceived that $25-50 \%$ of the patients did not adhere to the treatment for BTcP. Adherence to background pain treatments was high, although many oncologists considered that patients usually stopped taking the medication when feeling better. The main reported reasons for non-adherence were the self-perceived feeling that treatment was unnecessary, perceived inefficacy of the treatment, concerns about potential adverse effects, and lack of family support.

Conclusions: Oncologists perceived that adherenceto BTcP treatment can be improved and recommended treatment of adverse effects, better education about pain management to patients and relatives, written prescription instructions, and simplification of drug regimens.

Key words: Opioids, breakthrough cancer pain, therapeutic adherence, palliative care.
Resultados: Los oncólogos ( $\mathrm{n}=97$ ) indicaron que su primera opción para el DIO fue el fentanilo (varias formulaciones), con alta tolerancia ( $>76 \%$ de los pacientes). La mayoría de los oncólogos (96,8 \%) evaluaron la adherencia en sus pacientes, pero solo el 69,1\% siem- pre prescribió medicamentos para prevenir los efectos adversos de los opioides, y solo el 74,2 \% siempre tituló la dosis mínima. La mayoría de los oncólogos [51\%] percibieron que el 25-50 \% de los pacientes no mos- traban buena adherencia al tratamiento para DIO. La adherencia a los tratamientos de dolor basal fue alta, aunque muchos oncólogos consideraron que los pacien- tes generalmente dejaban de tomar el medicamento cuando se sentían mejor. Las principales razones para la no adherencia fueron la sensación de que el tra- tamiento era innecesario, la ineficacia percibida del tratamiento, la preocupación por los posibles efectos adversos y la falta de apoyo familiar.

Conclusiones: Los oncólogos percibieron que la adherencia al tratamiento para el DIO puede mejorarse y recomendaron el tratamiento de los efectos adversos de la medicación, una mejor educación sobre el manejo del dolor a los pacientes y familiares, instrucciones escritas de prescripción y simplificación de los regímenes de medicamentos.

Palabras clave: Opioides, dolor irruptivo oncológico, adherencia terapéutica, cuidados paliativos.

\section{INTRODUCTION}

It is estimated that $30-40 \%$ of cancer patients present pain at the moment of diagnosis, reaching $70-80 \%$ as the disease progresses $(1,2)$. Even when background cancer pain is adequately managed, brief episodes of acute pain, called breakthrough pain, can severely impact the quality of life of the patient. Breakthrough cancer pain (BTCP) has been defined as "a transient exacerbation of pain that occurs either spontaneously, or in relation to a specific predictable or unpredictable trigger, despite relatively stable and adequately controlled background pain" $(3,4)$. Despite recent major progress in the awareness and treatment of BTcP, it has been estimated that the prevalence of $\mathrm{BTCP}$ can reach up to $95 \%$ depending on the type of cancer and the diagnostic criteria, and about 60-90\% of cancer patients eventually die with pain (5-7). BTcP can have negative effects on the patient's physical functions and mood, which can lead to anxiety depression and sleep disorders (ㄹ). If not managed adequately, it is also associated with greater use of health services and social services [8].

The recommendations for the treatment of BTcP have been described in numerous studies and guidelines $(4,9-12)$. BTcP should be treated with a powerful analgesic with a rapid onset of action $[\leq 10$ minutes] and a short duration of effect $(\leq 2$ hours), with minimal side effects and easy to administer (comfortable, non-invasive and self-administered) (10). Generally, it is recommended that the management of patients with BTcP should include close monitoring of the patient's state from the very early stages of treatment [< 72 hours from start), during dose titration, and dynamically in subsequent stages of the disease. It was also emphasized that treatment should be individualized to fit each patient's specific needs, and recorded in his/ her medical history (10).

Studies aimed at determining the awareness and knowledge of the guidelines for the treatment of BTcP by practicing oncologists show that, despite general agreement on the guidelines' recommendations, compliance is limited and additional efforts are required to enhance its implementation $(8,13-16)$. Success in the management of BTcP episodes will depend on their adequate identification and evaluation, as well as a correct adherence to treatment (17). Some of the reasons for not taking the medication in patients with treatment for BTcP include the lack of perceived efficacy and fears about adverse effects, overdose and addiction $(18,19)$. However, adherence to treatment can be optimized through patient education, improved management patterns and better communication between doctors and patients [20]. Although many studies have evaluated 
the adherence to treatment for chronic pain in cancer patients, there are no studies on the adherence to opioid treatment directed at BTcP episodes.

The main objective of this study was to evaluate the perception of Spanish oncologists on adherence to opioid treatment for BTcP. Our study also examined how oncologists assess adherence and what interventions for improvement are usually carried out in their usual clinical practice. The analysis of these data will help in the design or improvement of strategies for cancer pain management which ultimately will increase the quality of life of the patient.

\section{MATERIALS AND METHODS}

This observational, multicentric study was carried out in 84 hospitals throughout Spain from September to November of 2017. Data was collected with an online questionnaire in which practicing oncologists actively involved in pain management responded to questions relative to their perception of treatment adherence and its management in current clinical practice. All the participating oncologists reported on pain management in patients with a diagnosis of cancer and currently with episodes of BTcP. The participant oncologists were chosen to be representative of all regions of Spain. The survey questions were developed by a Scientific Commit- tee comprised of members from Fundación ECO (Foun- dation for Excellence and Quality in Oncology), which is composed of expert oncologists. Survey questions were developed for the study by consensus among the members of the Scientific Committee, and were not formally validated.

This study was carried out following the ethical principles established in the current revised version of the Declaration of Helsinki (Ethical Principles for Medical Research in Humans, Seoul 2008) and Good Clinical Practice standards ( $\mathrm{ICH}$ harmonized tripartite guideline: Guideline for Good Clinical Practice, 1996). The study protocol was approved by the Ethics Commission for Clinical Studies of the Puerta del Hierro Hospital (Madrid, Spain).

\section{Outcome variables}

The main variable was the physician's perception of the degree of adherence by their patients of their opioid-based BTcP treatment.

Secondary variables were: a] the physician's perception of the adherence to the opioid-based treatment of background oncologic pain; b] the opioid treatment prescribed to patients with BTcP; c) the clinical consequences of therapeutic non-adherence, and the pharmacologic and non-pharmacologic factors involved in non-adherence; d) determination of how the oncologists evaluate adherence; e) the actions and strategies followed to improve therapeutic adherence in current clinical practice by the participant oncologists; and f), the differences in perception of adherence, type of opioid used, and possible prescription of preventive measures to manage adverse reactions, as a function of the years of practice and specialty of the participating physician.

\section{Study design and data collection}

All the data used in this study was collected by means of an online questionnaire which included questions on the demographic information of each of the participating oncologists and 25 questions related to their perception of adherence of the opioid treatment of cancer treatment and their current clinical practice. Of the 25 questions related to the perception of adherence, 20 questions were closed, 2 questions were open, and 3 were questions were to be responded according to a verbal rating scale (VRS). The VRS was used to measure a) the patients perceived efficacy of the opioids used to treat BTcP, b] the perceived concern of the patients about possible adverse effects of the opioids used to treat BTcP, and c) the patients concern about the possibility of addiction caused by the opioids. The questionnaire was designed as simple questions that reflect perceptions about the use of analgesics for the treatment of pain. We did not include questions about quality of life as they would not only reflect pain but also other aspects of the cancer treatment.

Each participating physician recorded the percentage of patients that followed the prescription of BTcP treatment and took the opioids at the doses and recommended intervals. Compliant patients were defined as those that follow the prescription in at least $80 \%$ of BTcP episodes.

The physician also recorded the percentage of patients that follow the prescription for the treatment of background oncologic pain, including patients that sometimes forget to take the prescribed medication, take the medication at the prescribed times, fail to take the medication when they feel well or fail to take the medication if it makes them feel unwell.

\section{Statistical analysis}

An analysis of descriptive statistics was presented for all the variables. The continuous variables were summarized by $\mathrm{N}$, mean and standard deviation (SD). The categorical variables were described by $\mathrm{N}$ and percentage of each category. All the tables, figures or graphs were calculated from the number of valid cases $(\mathrm{N})$, and this number is the one that was considered for the calculation of percentages or other statistical considerations.

All statistical analyzes were performed using the statistical package SAS ${ }^{\odot}$ (Statistical Analysis System) for Windows version 9.2 or later.

\section{RESULTS}

This study analyzed the perception of adherence to opioid treatments for BTcP of 97 oncologists working in 84 public and private Spanish hospitals (response rate $=70.29 \%$; 138 oncologists initially approached for the study). Their demographic data is shown in Table I. Most of the participants were women (60.8\%) aged 30-45 years and with 5-15 years of experience in their profession. Oncologists included specialists in all areas of cancer treatment. 
TABLE I

DEMOGRAPHIC DATA OF THE ONCOLOGISTS INTERVIEWED IN THIS STUDY ( $\mathrm{N}=97$ )

\begin{tabular}{|l|c|}
\hline & $N(\%)$ \\
\hline Gender (women) & $59(60.8)$ \\
\hline Age (years) & $3(3.1)$ \\
\hline$<30$ & $74(76.3)$ \\
\hline $30-45$ & $20(20.6)$ \\
\hline$>45$ & $15(15.5)$ \\
\hline Experience (years) & $60(61.9)$ \\
\hline $1-5$ years & $22(22.7)$ \\
\hline $5-15$ &
\end{tabular}

\section{Opioid treatments}

The preferred use of opioids for the treatment of cancer-related background pain and of BTCP is shown in Table II. For background pain, most oncologists reported using fentanyl as a first choice, morphine as second choice and oxycodone as third choice. For BTcP, oncologists mostly prescribed sublingual fentanyl as a first choice, nasal fentanyl as a second choice, and oral fentanyl or fast-acting morphine as third choice.

In general tolerance for the specific opioid treatment for BTcP was high, as $59.8 \%$ of the oncologists reported good tolerance for $>76 \%$ of the patients. Medication to prevent opioid-dependent adverse effects was prescribed by $69.1 \%$ of the oncologists, and the rest (29.9\%) reported doing it sometimes. Opioid dose titration to the minimum necessary was also done by most oncologists (74.2\%) but 21.6\% reported doing it only sometimes and $4.1 \%$ reported never doing it. When BTCP episodes persisted, $95.9 \%$ of the oncologists considered dose adjustments of the BTCP treatment.

\section{Adherence to the opioid treatment}

The physicians reported that adherence to therapy was evaluated by a direct interview with the patient [96.8\%) or a specific questionnaire (1.1\%). Only 2.1 $\%$ of the oncologists reported that adherence was not measured in their current clinical practice.

The adherence to the treatment for opioids for BTcP or background treatments is shown in Figure 1. Most oncologists (87.5\%) perceived that $>50 \%$ patients followed prescription instructions and took the correct dose of medication at recommended time intervals. However, many oncologists (51.0\%) perceived that a significant fraction of the patients (25-50\%), did not adhere to the treatment. The oncologists reported high adherence for background pain opioids, although most consider that their patients stop taking medication if it makes them feel unwell or if they feel better.

\section{Lack of adherence to opioid treatments}

Most oncologists (89.6\%) considered that therapeutic non-adherence significantly worsened the progression of their patients with respect to BTCP, with loss of quality of life as main consequence (87.5\%) and deterioration of family and social relations and prognosis as secondary consequences (Table III).

The main non-pharmacological factors that hindered therapeutic adherence in the patients were, according to the oncologists, the self-perceived feeling that they do not need being treated (35.8\%), the lack of family support (31.6\%), and the lack of disease awareness (26.3\%) (Table III). Conversely, the main pharmacolo-

TABLE II

OPIOID TREATMENTS PREFERRED BY SPANISH ONCOLOGISTS

\begin{tabular}{|c|c|c|c|}
\hline & $\begin{array}{c}1^{\text {st }} \text { choice } \\
N[\%]\end{array}$ & $\begin{array}{c}2^{\text {nd }} \text { choice } \\
N[\%]\end{array}$ & $\begin{array}{c}3^{\text {rd }} \text { choice } \\
N[\%]\end{array}$ \\
\hline \multicolumn{4}{|c|}{ Background pain treatment ${ }^{1}$} \\
\hline Fentanyl & 52 (53.0) & 29 (29.9) & $11(11.6)$ \\
\hline Morphine & $25(25.8)$ & 41 (42.3) & $18(18.9)$ \\
\hline Oxycodone & $12(12.4)$ & $17(17.5)$ & 48 (50.5) \\
\hline Other & 8 (8.3) & $10(10.3)$ & $18(18.7)$ \\
\hline \multicolumn{4}{|l|}{ BTcP treatment ${ }^{2}$} \\
\hline Sublingual fentanyl & 72 (75.0) & $19(19.8)$ & 3 (3.2) \\
\hline Nasal fentanyl & $12(12.5)$ & 42 (43.8) & $19(20.4)$ \\
\hline Oral fentanyl & 7 (7.3) & $13(13.5)$ & $28(30.1)$ \\
\hline Fast-acting morphine & 5 (5.2) & $20(20.8)$ & 26 (28.0) \\
\hline Fast-acting oxycodone & 0 & $2(2.1)$ & 16 (17.2) \\
\hline
\end{tabular}

${ }^{1}$ Data missing: 3rd choice for 2 participants. ${ }^{2}$ Data missing: 1st and 2nd choice for 1 participant, 3rd choice for 4 participants. 


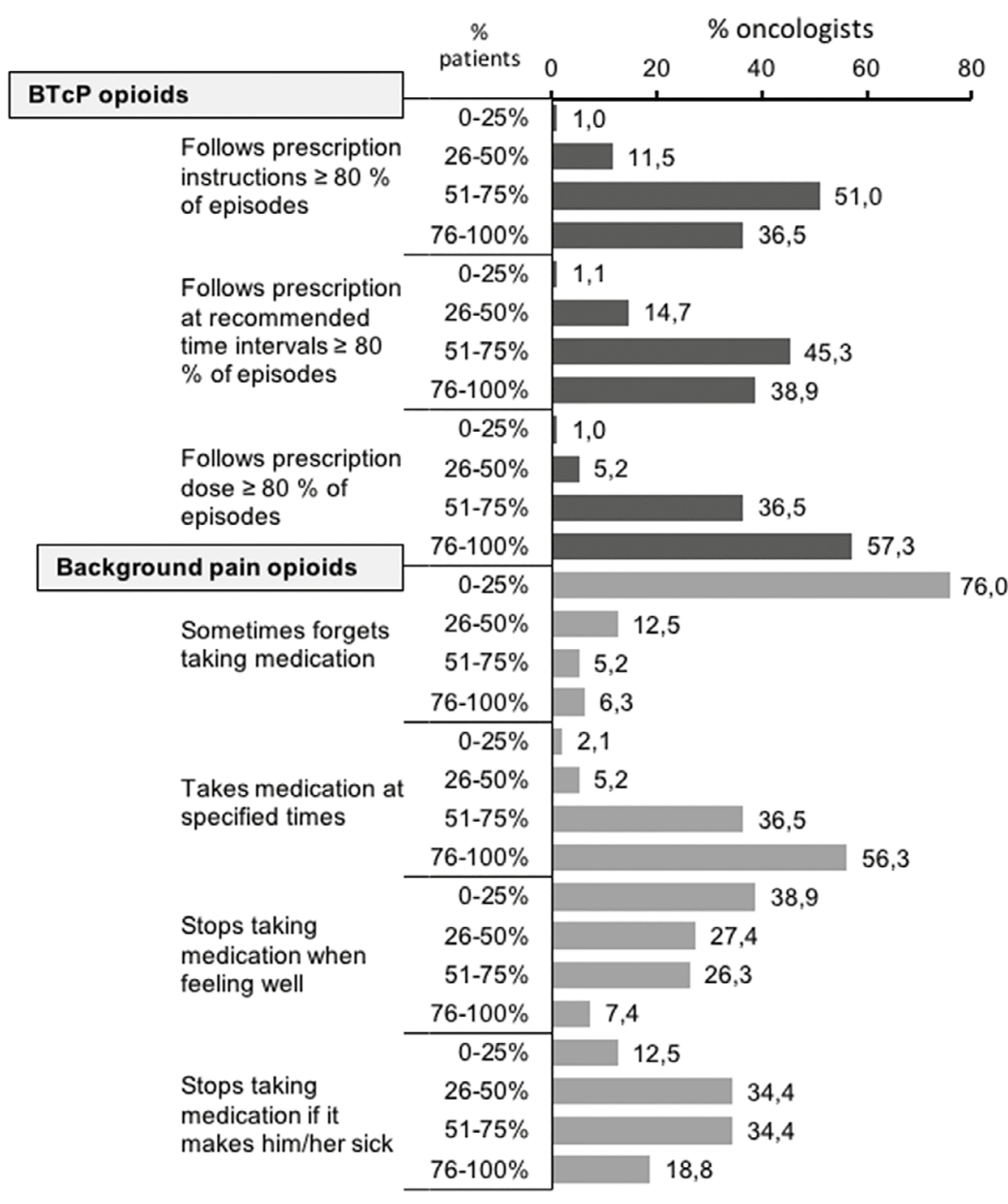

Fig. 1. Evaluation of adherence by the oncologists. The bars represent the percentage of oncologists who perceive a certain behavior in their patients with respect to opioid treatments for BTcP (top panel) or background pain (bottom panel).

gical factors that hindered adherence were perceived inefficacy of the treatment $[37.5 \%$, concern about potential adverse effects (32.3\%), and potential addiction to the opioids (10.4\%), among others (Table III).

\section{Adequacy of the treatment}

On a scale of 0-10 (10 = highly effective on a verbal rating scale), the physicians reported that their patients perceived that the efficacy of the opioids used to treat $\mathrm{BTCP}$ was (mean $\pm \mathrm{SD}$ ) $7.51 \pm 0.77$. Additionally, on a scale of 0-10 (10 = highly concerned), the oncologists reported that the concern of their patients about possible adverse effects of the opioids used to treat BTcP was $6.69 \pm 1.94$. Finally, asked about the possibility of addiction caused by the opioids, the physicians reported that their patients' concern, on a scale of 0-10 $110=$ highly concerned), was 6.0.

\section{Interventions to improve adherence}

Most oncologists (79.2 \%) indicated that their patients should receive more information on the medications prescribed to manage their pain. When asked about the interventions required to improve adherence to opioid treatment, the oncologists reported several possible options: treatment of adverse effects (88.7\%), education about pain management to patients and relatives (85.6\%), written prescription instructions (85.6\%), and simplification of drug regimens [84.6\%) (Table III).

Most oncologists (> $60 \%$ ) reported that the nurses are also involved in the education to patients and 
TABLE III

EVALUATION BY ONCOLOGISTS OF CONSEQUENCES OF NON-ADHERENCE, FACTORS THAT CONTRIBUTE TO DECREASE OF ADHERENCE, AND POSSIBLE INTERVENTIONS ( $\mathrm{N}=96$ )

\begin{tabular}{|c|c|}
\hline & $N[\%]$ \\
\hline \multicolumn{2}{|l|}{ Consequences of non-adherence to opioid treatment ${ }^{1}$} \\
\hline Worsening of the prognosis & 6 (6.3) \\
\hline Worsening of family and social relationships & $5(5.2)$ \\
\hline Decrease in quality of life & 84 (87.5) \\
\hline Increase in use of healthcare resources & $1(1.0)$ \\
\hline \multicolumn{2}{|l|}{ Non-pharmacological factors that decrease adherence ${ }^{2}$} \\
\hline Lack of disease awareness & 25 (26.3) \\
\hline Lack of family support & 30 (31.6) \\
\hline Lack of need for self-perceived treatment & 34 (35.8) \\
\hline Cognitive impairment & 3 (3.2) \\
\hline Difficulty of access to healthcare professionals & $1(1.1)$ \\
\hline Poor healthcare professional-patient relationship & $2(2.1)$ \\
\hline \multicolumn{2}{|l|}{ Pharmacological factors that decrease adherence1 } \\
\hline Perceived lack of efficacy of treatment & 36 (37.5) \\
\hline Concern about adverse events & 31 (32.3) \\
\hline Concern about addiction & $10(10.4)$ \\
\hline Complicated therapeutic guidelines & $15(15.6)$ \\
\hline Routes of administration & $2(2.1)$ \\
\hline Interactions with other medication & $2(2.1)$ \\
\hline \multicolumn{2}{|l|}{ Suggested interventions to improve adherence 1,3 } \\
\hline Education to patients and family about pain and its treatment & 83 (85.6) \\
\hline Written instructions on therapeutic guidelines & 83 (85.6) \\
\hline Motivational strategies & 19 (19.6) \\
\hline Improve physician-patient relationship & 62 (63.9) \\
\hline Simplification of therapeutic guidelines & 82 (84.6) \\
\hline Treatment of side effects & 86 (88.7) \\
\hline Adherence monitoring & 61 (62.9) \\
\hline Other & $4(4.1)$ \\
\hline
\end{tabular}

${ }^{1} \mathrm{~N}$ missing $=1 .{ }^{2} \mathrm{~N}$ missing $=2$. ${ }^{3}$ Participants could choose more than one option.

relatives, as well as in tasks related to support and guidance of patients.

\section{DISCUSSION}

This study evaluated various aspects of management of $\mathrm{BTCP}$ and the perception of therapeutic adherence by oncologists working in Spanish hospitals. Our study revealed that, although adherence to the opioid-based treatments for background pain and to BTcP is generally high, several issues require further attention and improvement.

One of the findings of our study was that there is still a significant fraction of oncologists that do not prescribe preventive treatment of characteristic opioid-related adverse reactions (nausea, vomiting, consti- pation) when administering opioids for BTcP. This pre- ventive treatment is advised in all current guidelines $[3,4,10,21,22)$. Also recommended in the guides is dose titration, which our study finds that almost 25 $\%$ of the participating oncologists do not do or do only occasionally. However, titration can be done rapidly and safely with current formulations of fentanyl (sublingual or nasal) which the oncologists prefer as first choice for the treatment of BTcP (12). Adequate titration of dose could help reduce side effects and reassure the patient that the treatment is effective and individualized for his/her condition. 
The pharmacologic profile of fentanyl is the most adequate for the treatment BTcP, but $5.1 \%$ of the oncologists use fast-acting morphine as a first choice. The percentage of Spanish oncologists choosing morphine increased to $25 \%$ when asked for second or third choice of drug for BTcP. However, fast acting morphine, because of it hydrophilic nature, has analgesic effects (slow onset of analgesia and prolonged duration of effect] that correlate poorly with typical BTcP episodes $(4,23)$. Current European Society for Medical Oncology (ESMO) guidelines indicate that transmucosal fentanyl formulations have a role in unpredictable and rapid-onset $\mathrm{BTcP}$ [21]. It is possible that some patients could stop taking opioids if they feel that the treatment is not effective against their BTcP. Most studies show that transmucosal formulations of fentanyl provided the strongest and fastest pain relief as compared to oral morphine for BTcP (24).

$\mathrm{BTcP}$ treatment should be reassessed regularly so that adjustments can be introduced as the disease progresses. This reassessment should not only take into account the analgesia, but also changes in quality of life of the patient, side effects, and patient's satisfaction (12). In this regard, our study showed that the oncologists perceived that patients were generally satisfied with the treatment, although to some extent concerned about side effects or addiction. Characteristic fears of the patients were adverse effects associated with the treatment or the possibility of addiction, as it has been described in other studies $(18,19)$. It is also possible that disease prognosis could influence the adherence to the treatment. In patients with better prognosis perhaps the use and type of BTcP medication should be adapted to the expected length of treatment, therefore limiting the potential adverse effects of longer exposures, such as the possibility of addiction.

Communication skills can also aid the physician improve adherence and critically influence the patient's approach to opioid therapy (19). For example, providing both written and verbal information about pain management plans have been shown to be important [25]. A large majority of oncologists emphasized the need for written instructions on BTcP management and better education to patients, stressing the deficiencies in the current process. In our study, although most oncologists advocated giving their patients more information, it was not specified who or when should provide this information. Our study showed that nurses have a significant role in education of patients and relatives, but it is uncertain if they are ready to perform this role or the effectiveness of their participation. In fact, a study of nurses' practices across 12 European countries (but not including Spain] showed that they are often unprepared to deal with BTcP (26). Even if this study was focused on oncologic BTcP exclusively from perspective of oncologists, if should be of interest in future studies to include other professionals involved in Pain Units in Spanish hospitals, thus reflecting their multidisciplinary nature.

One of the limitations of our study was that the oncologist could be biased in his quantitative response of the adherence if he did not keep detailed records of the number of patients with BTcP treated and interviewed on this issue. Also, the details of the interaction with the patient were not specified or standardized. As it is common with self-reported data, it could also be subject to bias by the 'Hawthorne effect', by which oncologists could have modified their behavior in response to their awareness of being observed (그). However, the strengths of the study include a high number of representative oncologists of all regions of Spain and also that the study was designed to provide insights on the current, real world, practices in Spain.

\section{CONCLUSIONS}

Oncologists perceived that adherence to BTcP treatment by their patients could be strengthened by improved treatment of adverse effects, better education about pain management to patients and relatives, providing written prescription instructions, and simplification of drug regimens to improve adherence.

\section{ACKNOWLEDGMENTS}

The authors acknowledge all the oncologists who participated in the survey for their contribution to the study. The authors thank Francisco de López de Saro (Trialance SCCL) for medical writing support.

\section{DATA AVAILABILITY}

The data used to support the findings of this study are available from the corresponding author upon request.

\section{FUNDING}

This study was funded by Kyowa Kirin Farmacéutica SLU through the Fundación ECO (Foundation for Excellence and Quality in Oncology, Spain].

\section{CONFLICT OF INTEREST}

The authors declare no conflict of interest.

\section{ETHICAL APPROVAL}

The study protocol was approved by the Ethics Commission for Clinical Studies of the Puerta del Hierro Hospital (Madrid, Spain).

\section{REFERENCES}

1. Breivik H, Cherny N, Collett B, de Conno F, Filbet M, Foubert $A J$, et al. Cancer-related pain: a pan-European survey of prevalence, treatment, and patient attitudes. Ann Oncol. 2009;20(8):1420-33. DOI: 10.1093/annonc/mdp001.

2. Greco MT, Roberto A, Corli O, Deandrea S, Bandieri E, Cavuto S, et al. Quality of cancer pain management: an update of a systematic review of undertreatment of patients with cancer. J Clin Oncol. 2014;32(36):4149-54. DOI: 10.1200/ JCO.2014.56.0383. 
3. Davies AN, Dickman A, Reid C, Stevens AM, Zeppetella $G$. The management of cancer-related breakthrough pain: recommendations of a task group of the Science Committee of the Association for Palliative Medicine of Great Britain and Ireland. Eur J Pain. 2009;13(4):331-8. DOI: 10.1016/j. ejpain.2008.06.014.

4. Jara C, Del Barco S, Gravalos C, Hoyos S, Hernandez B, Munoz $M$, et al. SEOM clinical guideline for treatment of cancer pain. Clin Transl Oncol. 2018;20(1):97-107. DOI: 10.1007/s12094-017-1791-2.

5. Oldenmenger WH, Sillevis Smitt PA, van Dooren S, Stoter $G$, van der Rijt CC. A systematic review on barriers hindering adequate cancer pain management and interventions to reduce them: a critical appraisal. Eur $\mathrm{J}$ Cancer. 2009;45(8):1370-80. DOI: 10.1016/j.ejca.2009.01.007.

6. Margarit C, Julia J, Lopez R, Anton A, Escobar Y, Casas A, et al. Breakthrough cancer pain - still a challenge. J Pain Res. 2012;5:559-66. DOI: 10.2147/JPR.S36428.

7. Deandrea S, Corli O, Consonni D, Villani W, Greco MT, Apolone $\mathrm{G}$. Prevalence of breakthrough cancer pain: a systematic review and a pooled analysis of published literature. J Pain Symptom Manage. 2014;47(1):57-76. DOI: 10.1016/j. jpainsymman.2013.02.015.

8. Davies A, Buchanan A, Zeppetella G, Porta-Sales J, Likar R, Weismayr W, et al. Breakthrough cancer pain: an observational study of 1000 European oncology patients. J Pain Symptom Manage. 2013;46(5):619-28. DOI: 10.1016/j. jpainsymman.2012.12.009.

9. Boceta J, De la Torre A, Samper D, Farto M, Sanchez-de la Rosa R. Consensus and controversies in the definition, assessment, treatment and monitoring of BTcP: results of a Delphi study. Clin Transl Oncol. 2016;18(11):1088-97. DOI: 10.1007/s12094-016-1490-4.

10. Escobar Y, Biete A, Camba Rodríguez M, Galvez R, Mañas A, Rodriguez Sanchez C, et al. Diagnosis and treatment of breakthrough cancer pain: Consensus recomendations. Rev Soc Esp Dolor. 2013;20(2):61-8. DOI: 10.4321/ S1134-80462013000200005. DOI: 10.4321/S113480462013000200005.

11. Swarm RA, Paice JA, Anghelescu DL, Are M, Bruce JY, Buga S, et al. NCCN Clinical Practice Guidelines in Oncology: Adult Cancer Pain. Version 1.2018. Available at: NCCN.org. Accessed November 14, 2018.

12. Vellucci R, Fanelli G, Pannuti R, Peruselli C, Adamo S, Alongi $G$, et al. What to Do, and What Not to Do, When Diagnosing and Treating Breakthrough Cancer Pain (BTcP): Expert Opinion. Drugs. 2016;76(3):315-30. DOI: 10.1007/s40265015-0519-2.

13. Bedard G, Davies A, McDonald R, Hawley P, Buchanan A, Popovic $M$, et al. Breakthrough cancer pain: a comparison of surveys with European and Canadian patients. Support Care Cancer. 2015;23(3):791-6. DOI: 10.1007/s00520014-2426-6.

14. Greco MT, Corli O, Montanari M, Deandrea S, Zagonel V, Apolone G. Epidemiology and pattern of care of breakthrough cancer pain in a longitudinal sample of cancer patients: results from the Cancer Pain Outcome Research Study Group. Clin J Pain. 2011;27(1):9-18. DOI: 10.1097/ AJP.Ob013e3181edc250.
15. Kim DY, Ahn JS, Lee KH, Kim YC, Lee J, Kim SY. A nationwide survey of knowledge of and compliance with cancer pain management guidelines by korean physicians. Cancer Res Treat. 2014;46(2):131-40. DOI: 10.4143/ crt.2014.46.2.131.

16. López López R, Camps Herrero C, Khosravi-Shahi P, Guillem Porta V, Carrato Mena A, García-Foncillas J, et al. Oncologist's knowledge and implementation of guidelines for breakthrough cancer pain in Spain: CONOCE study. Clin Transl Oncol. 2018;20(5):613-8. DOI: 10.1007/s12094- 0171756-5.

17. Timmerman L, Stronks DL, Groeneweg JG, Huygen FJ. Prevalence and determinants of medication non-adherence in chronic pain patients: a systematic review. Acta Anaesthesiol Scand. 2016;60(4):416-31. DOI: 10.1111/aas. 12697.

18. Davies AN, Vriens J, Kennett A, McTaggart M. An observational study of oncology patients' utilization of breakthrough pain medication. J Pain Symptom Manage. 2008;35(4):40611. DOI: 10.1016/j.jpainsymman.2007.05.010.

19. Rhiner MI, von Gunten CF. Cancer breakthrough pain in the presence of cancer-related chronic pain: fact versus perceptions of health-care providers and patients. J Support Oncol. 2010;8(6):232-8. DOI: 10.1016/j.suponc.2010. 10.006 .

20. Oldenmenger $W H$, Sillevis Smitt PAE, de Raaf PJ, van der Rijt CCD. Adherence to Analgesics in Oncology Outpatients: Focus on Taking Analgesics on Time. Pain Pract. 2017;17(5):61624. DOI: 10.1111/papr.12490.

21. Fallon M, Giusti R, Aielli F, Hoskin P, Rolke R, Sharma $M$, et al. Management of cancer pain in adult patients: ESMO Clinical Practice Guidelines. Ann Oncol. 2018 Oct 1;29(Supplement_4):iv166-iv91. DOI: 10.1093/annonc/ mdy152.

22. Mercadante S, Radbruch L, Caraceni A, Cherny N, Kaasa $S$, Nauck F, et al. Episodic (breakthrough) pain: consensus conference of an expert working group of the European Association for Palliative Care. Cancer. 2002;94(3):832-9. DOI: 10.1002/cncr. 10249.

23. Vellucci R, Mediati RD, Gasperoni S, Mammucari M, Marinangeli F, Romualdi P. Assessment and treatment of breakthrough cancer pain: from theory to clinical practice. J Pain Res. 2017;10:2147-55. DOI: 10.2147/JPR. S135807.

24. Mercadante S. Treating breakthrough pain in oncology. Expert Rev Anticancer Ther. 2018;18(5):445-9. DOI: 10.1080/14737140.2018.1443813.

25. Carulla Torrent J, Jara Sanchez C, Sanz Ortiz J, Batista Lopez N, Camps Herrero C, Cassinello Espinosa J, et al. Oncologists' perceptions of cancer pain management in Spain: the real and the ideal. Eur J Pain. 2007;11(3):3529. DOI: 10.1016/j.ejpain.2006.05.006.

26. Rustoen T, Geerling Jl, Pappa T, Rundstrom C, Weisse I, Williams SC, et al. A European survey of oncology nurse breakthrough cancer pain practices. Eur J Oncol Nurs. 2013;17(1):95-100. DOI: 10.1016/j.ejon.2012.05.005.

27. McCarney R, Warner J, lliffe S, van Haselen R, Griffin M, Fisher P. The Hawthorne Effect: a randomised, controlled trial. BMC Med Res Methodol. 2007;7:30. DOI: 10.1186/14712288-7-30. 